\title{
Correlation of Maternal Hemoglobin with Birth Weight: A Hospital Based Study
}

\author{
Hamzullah Khan, Khalid Khan, Neelum Shehzadi, Huma Riaz

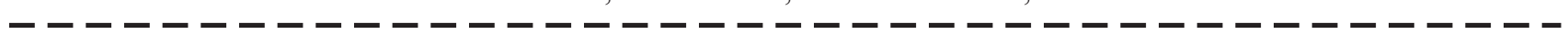

ABSTRACT:

Objectives: To determine the correlation of maternal Hemoglobin concentration in labor with birth weight.

Study design and setting: This was cross sectional study conducted in Qazi Hussain Ahmed Medical Complex, (QHAMC) Medical Teaching Institution Nowshera, from $20^{\text {th }}$ April 2019 to $31^{\text {st }}$ Jan 2020.

Methodology: A total of 254 deliveries were assessed. All pregnant ladies in labor, presenting to labor room of QHAMC Nowshera, irrespective of age were included. The weight of babies was recorded at birth. Pearson correlation and logistic regression and relative risk analysis were used to show the relationship and probability of occurrence of low birth weight babies in anemic and non anemic patients.

Results: The mean with standard deviation of hemoglobin in mothers was $10.76+1.63 \mathrm{~g} / \mathrm{dl}$. The mean with standard deviation of birth weight was $2.71+0.6 \mathrm{~kg}$. The frequency of low birth weight babies was $68(26.77 \%)$ with weight less than $2500 \mathrm{~g}$ at birth. A positive linear correlation of birth weight with level of hemoglobin of mother in labor was statistically significant $(\mathrm{p}=0.001, \mathrm{r}=0.35$ ). Using logistic regression analysis, it was observed that the probability of LBW in pregnant women with hemoglobin $<11 \mathrm{~g} / \mathrm{dl}$ was 3.31 times higher $(p=0.001, \mathrm{OR}=3.31)$.

Conclusion: The frequency of LBW is $26.7 \%$ markedly higher and maternal anemia is a risk factor for it. The relative risk is 2.4 times higher in anemic pregnant ladies as compared to the non anemic mother.

Key words: Low birth weight, Iron deficiency anemia, Risk analysis

- - - - - - - - - - - - - - - - - - - - - - - - - - - -

How to cite this Article:

Khan H, Khan K, Shehzadi N, Riaz H. Correlation of Maternal Hemoglobin with Birth Weight: A Hospital Based Study. J Bahria Uni Med Dental Coll. 2021; 11(1):13-16 DOI: https://doi.org/10.51985/MZMI4908

This is an Open Access article distributed under the terms of the Creative Commons Attriution Non Commercial Liciense (http:// creativecommons/org/licences/by-nc/4.0) which permits unrestricted non commercial use, distribution and reproduction in any medium, provided the original work is properly cited.

\section{- - - - - - - - - - - - - - - - - - - - - - - - - - -}

\section{INTRODUCTION:}

The causes of low birth weight are multifactorial and many factor including; maternal, genetic and fetal can contribute and play vital role in this regard. These factors interplay with each other and contribute individually as well as in combination. ${ }^{1}$ A meta-analysis from different cohort and case control studies carried out in several countries of the world concluded that there is a statistically strong relationship of the maternal anemia with low birth weight. ${ }^{2}$ In general practice maternal anemia is defined as maternal hemoglobin less than $11 \mathrm{~g} / \mathrm{dl}$ during the gestational period. ${ }^{1,3,4}$. Regarding

Hamzullah Khan
Professor, Department of Hematology,
Nowshera Medical College, Nowshera Pakistan
Email: hamzakmc@gmail.com
Khalid Khan
Assistant Professor, Department of Pediatrics,
I I I
I Aseelum Shehzadi
I Nowshera Medical College, Nowshera Pakistan
I Huma Riaz
I Assistant Professor, Department of Hematology,
I Hayatabad Medical Complex, Peshawar.
I Received: 27-Oct-2020
I Accepted: 01-Dec-2020

the prevelance and definition of the low birth weight deliveries, a textbook Willium obstetrics reports 7 to $10 \%$ of the infants in the Unites state weight less than 2500grams irrespective of gestational age/anemia ${ }^{4}$. The prevelance of lowbirth weight in Pakistan is reported as $10.04 \%{ }^{5}$

In general, the biochemical parameters of maternal nutrition have minimal effects on the birth weight of offspring. However mean birth weight of the non anemic and anemic groups have statistically significant difference. ${ }^{1,4}$ Bhargava $\mathrm{V}$ et al reported that the desired weight of the babies is achieved in the body of the mother, that has a strong correlation with the the maternal $\mathrm{Hb} \%{ }^{6}$

The anemia of different gestational period has been reported to have an impact on the outcome, some have reported even the maternal anemia of the first trimester of pregnancy has a relationship to the deliveries of low birth weight babies, and the risk increases with the progression of anemia in next trimesters. ${ }^{7}$ A study from Turkey reported that low $\mathrm{Hb} \%$ of mother during the third trimester of pregnancy were strongly associated with low birth weight babies. They further reported that maternal anemia can be a direct cause of the deterioration of in-utero fetal growth due to lack of oxygen supply from the placenta to the fetal tissues. They extended their study and further reported that treatment of anemia during pregnancy is directly correlated with better outcomes in 
terms of birth weight. ${ }^{8}$ A cross sectional study from India reported 4.86 time higher risk of preterm and low birth weight babies in pregnamt women with severe anemia, followed by a risk of 3.18 time in pregnant ladies with moderate anemia. ${ }^{9}$

The prevelance of anemia in pregnant ladies in Pakistan reported as $29 \% .{ }^{10}$ Considering the high prevelance of anemia present study was aimed to determine the correlation of maternal hemoglobin concentration with birth weight of the newborn in a tertiary care hospital of Nowshera.

\section{METHODOLOGY:}

A cross sectional study was conducted in the Pathology department in collaboration with the Department of Gynecology and Obstetrics, Qazi Hussain Ahmed Medical Complex, Medical Teaching Institution Nowshera, from $20^{\text {th }}$ April 2019 to $31^{\text {st }}$ Jan 2020. Ethical approval for the survey was obtained from the Ethical Review Committee of Nowshera Medical College/QHAMC. ERC letter with reference number No-102, Dated 19 June 2019 was issued. Total number patients studied were 254.The calculated sample size was 139 on the basis of $10.04 \%$ prevelance of low birth weight in Pakistan. ${ }^{5}$ The inclusion criteria was all expecting women in labor, presenting to the labor room of QHAMC Nowshera, irrespective of age. While the expecting women taking oral or intravenous iron therapy for their already diagnosed Iron deficiency anemia were excluded. Blood samples were collected from these women. The technique for the blood sampling collection was to collect $3 \mathrm{ml}$ of venous blood using disposable syringes under aseptic techniques. The blood was added in an EDTA vacutainer and mixed gently. Complete blood count was calculated on hematology analyzer. Anemia was labeled when the pregnant women had a hemoglobin level of $<11 \mathrm{~g} / \mathrm{dl}$ in accordance with the definition of World Health Organization ${ }^{11}$. This study was conducted in collaboration of gynecology department and pediatric/nursery department. The weight of the baby (in $\mathrm{kg}$ ) after deliver was noted using manual weight machine and recorded in the patient file.The low birth weight was taken as weight less than $2.5 \mathrm{kgs}$ as defined by the World Health Organization (WHO). ${ }^{12}$

Data was entered in SPPS Version 25. Descriptive statistics were used for numerical variables like $\mathrm{Hb}$ and ferritin of mother and weight of babies. The independent t-test was used for hemoglobin and ferritin levels in gender groups. Nominal variable were the mode of delivery and gestational age were presented with frequency and percentages using pi-charts. The Pearson Correlation test was used to determine the correlation of hemoglobin concentration of mother with weight of babies.Regression analysis was used to determine the probability of low birth weight in anemic and non anemic groups. Relative risk (RR) was calculated for stratification of anemic and non anemic groups based on the concentration of hemoglobin in group with deliveries of low birth weight babies using risk analysis statistics.

\section{RESULTS:}

Total of 254 cases were studied. The mean with standard deviation of hemoglobin in mothers was $10.76+1.63 \mathrm{~g} / \mathrm{dl}$. The minimum $\mathrm{Hb} \%$ recorded was $6.2 \mathrm{~g} / \mathrm{dl}$ to a maximum of $18 \mathrm{~g} / \mathrm{dl}$ with a range of 11.8 . The mean with standard deviation of birth weight was $2.71+0.6 \mathrm{~kg}$. The minimum birth weight recorded was $1.5 \mathrm{~kg}$ to a maximum of $4.6 \mathrm{~kg}$ with a range of $2.1 \mathrm{~kg}$. (Table 1). It was observed that $68(26.77 \%)$ of the new born had weight less than $2500 \mathrm{~g}$, while $186(73.22 \%)$ had equal or more than $2500 \mathrm{~g}$ weight. Out of total 254 cases $229(90.2 \%)$ were in full term with gestation period of more than 37 weeks. $19(7.5 \%)$ were preterm with gestational history of less than 37 weeks, while $6(2.4 \%)$ were postterm. Figure1. Similarly, 234(92.1\%) casese delivered through Normal vaginal delivery (NVD), 14(5.5\%) through Cesarean -section) and 6(2.4\%) through forcep assisted deliveries (Figure 1)

The correlation of mother's hemoglobin with baby weight was assessed using Pearson correlation test and found a moderate uphill positive linear relation of birth weight with level of hemoglobin of mother at labour that was statistically significant $(p=0.001, \mathrm{r}=0.35)$.(Table 2$)$

Using logistic regression analysis to show the probability of occurrence of LBW in relation with hemoglobin concentration dividing the patients in 2 categories. One groups with $\mathrm{Hb} \%$ less than $11 \mathrm{~g} / \mathrm{dl}$ and another with more than $11 \mathrm{~g} / \mathrm{dl}$. It was observed that the probability of LBW in pregnant ladies with hemoglobin $<11$ was 3.31 times more than cases with $\mathrm{Hb}>11 \mathrm{~g} / \mathrm{dl}$. (p-value $0.001, \mathrm{OR}=3.31$ ). (Table 3) The risk analysis for low birth weight deliveries in anemic and non anemic categories taking $\mathrm{Hb} \%$ concentration in consideration were assessed. It was noted that the risk of low birth weight for cohort (category with $\mathrm{Hb}<11 \mathrm{~g} / \mathrm{dl}$ ) was 2.4 times as compared to 0.56 times in cohort (category with $\mathrm{Hb}>11 \mathrm{~g} / \mathrm{dl}$ ). The Odds ratio was 4.2 when measured with anemic mothers only. (Table 4)

\section{DISCUSSION:}

Intrauterine growth and development is most vulnerable process that affects and has a profound and lasting influence on the physical, mental and developmental growth after birth and in later life that largely depends on the maternal health and well being. we observed that the mean of hemoglobin in pregnant ladies in labor was $10.76+1.63 \mathrm{~g} / \mathrm{dl}$, that falls in anemic group as per definition of the WHO. ${ }^{11}$ Likewise $68(26.77 \%$ ) of the new born had weight less than $2500 \mathrm{~g}$. Many studies from Pakistan have reported low birth weight to have an established association with a group of maternal factors like weight and height of mother, socialeconomic status and maternal anemia. ${ }^{13,14}$ Our findings are higher than Khan $\mathrm{A}^{15}$ reported from Karachi as $10.6 \%$ of LBW deliveries and Najmi $\mathrm{RS}^{16}$ reported the prevelance of total LBW deliveries from Lahore as 19\%. UNDP reports the incidence of LBW deliveries as reported globally varies 
Table 1. Descriptive Statistics of Hemoglobin and birth weight

\begin{tabular}{|c|c|c|}
\hline & Hb of Mother & Babies weight at birth \\
\hline Number of patients & 254 & 254 \\
\hline Mean & 10.76 & 2.71 \\
\hline Median & 11 & 3 \\
\hline Mode & 11 & 3 \\
\hline Std. Deviation & 1.63 & 0.6 \\
\hline Range & 11.8 & 3.1 \\
\hline Minimum & 6.2 & 1.5 \\
\hline Maximum & 18 & 4.6 \\
\hline
\end{tabular}

a. Multiple modes exist. The smallest value is shown

Figure 1. Gestational history and Mode of Delivery

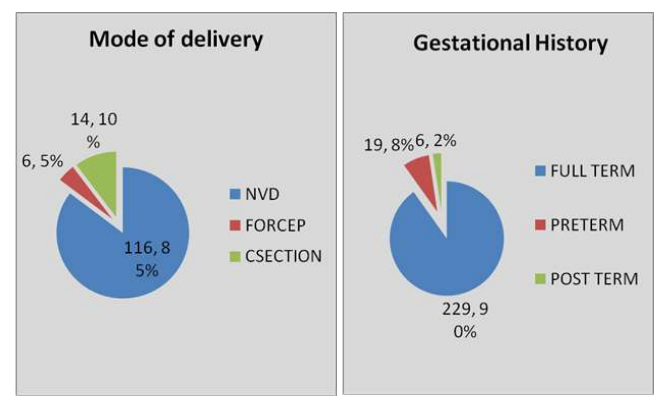

Table 2. Pearson Correlation of hemoglobin of mother with baby weight

\begin{tabular}{|c|c|c|}
\hline & & Birth weight \\
\hline \multirow{2}{*}{$\mathrm{Hb} \%$} & Pearson Correlation & $.347^{* *}$ \\
\cline { 2 - 3 } & Sig. (2-tailed) & 0.001 \\
\hline
\end{tabular}

**. Correlation is significant at the 0.01 level (2-tailed)

*. Correlation is significant at the 0.05 level (2-tailed)

Table 3. Regression analysis of the birth weight with anemia of mother

\begin{tabular}{|l|c|c|c|c|c|c|}
\hline \multicolumn{2}{|c|}{ Observed } & \multicolumn{3}{c|}{ Predicted } \\
\cline { 3 - 6 } & & \multicolumn{3}{c|}{ Hb Categories } \\
\hline \multirow{2}{*}{ Birthweight } & $<2.5 \mathrm{~kg}$ & 49 & $\mathrm{Hb}>11$ \\
\cline { 2 - 6 } & $>2.5 \mathrm{~kg}$ & 24 & 44 \\
\hline \multicolumn{5}{|c|}{ Variables In Equation } \\
\hline & B & S.E. & Wald & df & Sig. & $\operatorname{Exp}(\mathrm{B})$ \\
\hline Birthwt & 1.197 & 0.244 & 24.055 & 1 & 0 & 3.311 \\
\hline Constant & -2.637 & 0.653 & 16.296 & 1 & 0 & 0.072 \\
\hline
\end{tabular}

with 19\% in developed countries, 31\% from South Asia, followed by Africa \& north America 15\%. ${ }^{17}$

UNICEF reports that across the globe neonatal mortality increases by 20 times in newborn with low birth weight as compared to normal or heavier babies more than $2.5 \mathrm{~kg} .{ }^{13}$ In Pakistan the prevalence of LBW births varies from 5 to $23 \%$ in different parts. $^{18}$
Table 4. Risk Estimate of low birth babies in anemic and non anemic groups

\begin{tabular}{|l|c|c|c|}
\hline & \multirow{2}{*}{ Value } & \multicolumn{2}{|c|}{$\begin{array}{r}\text { 95\% Confidence } \\
\text { Interval }\end{array}$} \\
\cline { 3 - 4 } & & Lower & Upper \\
\hline $\begin{array}{l}\text { Odds Ratio for Weight } \\
\text { categories }(1.00 / 2.00)\end{array}$ & $\mathbf{4 . 2 8 8}$ & 2.488 & 7.390 \\
\hline $\begin{array}{l}\text { For cohort Hb\% category-1 } \\
=\mathrm{Hb}<11 \mathrm{~g} / \mathrm{dl}\end{array}$ & $\mathbf{2 . 4 0 9}$ & 1.733 & 3.350 \\
\hline $\begin{array}{l}\text { For cohort Hb\% category-2 } \\
=\mathrm{Hb}>11 \mathrm{~g} / \mathrm{dl}\end{array}$ & $\mathbf{. 5 6 2}$ & .440 & .718 \\
\hline
\end{tabular}

The correlation of mother's hemoglobin using Pearson correlation test was assessed and found a moderate uphill positive linear relation of birth weight with level of hemoglobin of mother at labor (P-value 0.001, $\mathrm{r}=0.35$ ). Lumbanraja SN et $\mathrm{al}^{19}$ observed that LBW was the only indicator out of multiple variables that statistically significantly correlated with Maternal anemia $(p<0.05)$ that matches our findings. Our findings also matched with a study from Rawalpindi that reported that a total of $64 \%$ LBW deliveries with a statistical correlation with anemia in the third trimester of gestation $(p=0.001){ }^{19}$

The same way, the probability of LBW in mother with hemoglobin $<11$ at labor, was 3.31 times more than mothers with $\mathrm{Hb}>11 \mathrm{~g} / \mathrm{dl}$. Lone et al reported from a multivariate analysis that the risk of LBW babies in anemic population is 1.9 times higher than non anemic population $(95 \% \mathrm{CI}=$ 1.0-3.4) that was in concordance with our findings. ${ }^{20}$

An article published in the Bulletin of world health orgnaization revealed an increased in incidence of LBW babies in anemic mothers, however the difference in anemic and non anemic mother in term of LBW deliveries was not statistically significant $(\mathrm{p}=0.112$ ). Failure to control a decline in $\mathrm{Hb}$ below $10 \mathrm{~g} / \mathrm{dl}$ was also associated with preterm deliveries and was considered as high risk for LBW outcome. $^{21}$

The risk of low birth weight for the cohort category with $\mathrm{Hb}<11 \mathrm{~g} / \mathrm{dl}$ ) was 2.4 times. Another local study from Punjab reported a higher risk of LBW in pregnant ladies with low hemoglobin in their last trimester. ${ }^{22}$ Another metaanlysis where 7243 articles were found in Medline, out of which 68 were selected for the study, revealed an increase in risk of LBW of 1.43 times associated with maternal anemia. ${ }^{23}$

There are few study limitations. Firstly, we were unable to check the serum ferritin levels of all the pregnant women in labor, therefore future studies should focus on the correlation of serum ferritin with the fetal weight at birth. Similarly, second limitation is that we were unable to separately explain the low birth weight and pre-term babies in both anemic and non anemic, so therefore the future 
research studies should focus on these two different groups (Pre-term and LBW) and identify its correlation with maternal $\mathrm{Hb}$ and ferritin that can help the decision maker to decide best in the interest of mother and child.

\section{CONCLUSION:}

The frequency of LBW is $26.7 \%$ markedly higher and maternal anemia is a risk factor for it. The relative risk is 2.4 times higher in anemic pregnant ladies as compared to the non anemic mother.

T Authors Contribution:

I Hamzullah khan: Concept design, data collection, data analysis, I manuscript writing

I Khalid Khan: Data Collection, manuscript writing, critical I review

Neelum Shehzadi: Data collection, manuscript writing, critical review

Huma Riaz: Manuscript writing, critical review

I ----------------1

\section{REFERENCES:}

1. Centers for Disease Control and Prevention report. Recommendations to prevent and control iron deficiency in the United States. Centers for Disease Control and Prevention.MMWR Recomm Rep. 1998 Apr 3; 47(RR-3):129.

2. Figueiredo ACMG, Gomes-Filho IS, Silva RB, et al. Maternal Anemia and Low Birth Weight: A Systematic Review and Meta-Analysis. Nutrients. 2018;10(5):601. doi:10.3390/ nu10050601

3. World Health Organization (WHO) The Global Prevalence of Anaemia in 2011. World Health Organization; Geneva, Switzerland: 2015

4. Cunningham FG, Leveno KJ, Bloom SL, Hauth JC, Gilstrap III L, Wenstrom KD. Williams's obstetrics. 22nd Ed. . Philadelphia: McGraw-Hill; 2005. pp. 1143-1167

5. Iltaf G, Shahid B, Khan MI. Incidence and associated risk factors of low birth weight babies born in Shaikh Khalifa Bin Zayad Al-Nayan Hospital Muzaffarabad, Azad Jammu and Kashmir. Pak J Med Sci. 2017;33(3):626-630.

6. Bhargava V, Chatterjee M, Prakash A, Bhatia BD, Mishra A. Fetal growth variations. I. Influence of maternal size and nutrition on identification of fetal growth retardation. Indian Pediatr 1983, 20: 549- 559.

7. Rahmati S, Delpishe A, Azami M, Hafezi Ahmadi MR, Sayehmiri K. Maternal Anemia during pregnancy and infant low birth weight: A systematic review and Meta-analysis. Int J Reprod Biomed. 2017;15(3):125-134.

8. Yildiz Y, Özgü E, Unlu SB, Salman B, Eyi EGY. The relationship between third trimester maternal hemoglobin and birth weight/length; results from the tertiary center in Turkey. The Journal of Maternal-Fetal \& Neonatal Medicine, 2014;17(7): 729-32.
9. Kumari S, Garg N, Kumar A, Guru PKI, Ansari S, Anwar S, Singh KP, Kumari P, Mishra PK, Gupta BK, Nehar S, Sharma AK, Raziuddin M, Sohail M. Maternal and severe anaemia in delivering women is associated with risk of preterm and low birth weight: A cross sectional study from Jharkhand, India. One Health. 2019 Aug 19;8:100098. doi: 10.1016/j.o nehlt.2019.100098. PMID: 31485474; PMCID: PMC6715890.

10. Baig-Ansari N, Badruddin SH, Karmaliani R, et al. Anemia prevalence and risk factors in pregnant women in an urban area of Pakistan. Food Nutr Bull. 2008;29(2):132-139. doi: $10.1177 / 156482650802900207$

11. World Health Organization, WHO Report (1997). Family and reproductive health coverage of maternity care. Geneva, WHO: 205-220.

12. World Health Organization. Physical Status: The Use and Interpretation of Anthropometry. Report of a WHO Expert Committee. Technical Report Series No. 854. Geneva, World Health Organization, 1995.

13. Yilgwan CS, Abok II, Yinnang WD, Vajime BA. Prevalence and risk factors of low birth weight in Jos. Jos J Med. 2009;4(1):13-15.

14. Khan N, Jamal M. Maternal risk factors associated with low birth weight. J Coll Physicians Surg Pak. 2003;13(1):25-28.

15. Khan A, Nasrullah FD, Jaleel R. Frequency and risk factors of low birth weight in term pregnancy. Pak J Med Sci. 2016; 32(1): 138-142

16. Najmi RS, Distribution of birthweights of hospital born Pakistani infants. J Pak Med Assoc. 2000, 50 (4): 121-124.

17. UNDP: Infants with low birth weight. Accessed December 17, 2006, [http://hdrstats.undp.org/indicators/67.html]

18. UNICEF: Low Birth Weight, Country Regional and Global estimates. Accessed July 13, 2005, [http://www.unicef.org /publications/index_24840.htm

19. Lumbanraja SN, Yaznil MR, Siregar DIS, Sakina A. The Correlation between Hemoglobin Concentration during Pregnancy with the Maternal and Neonatal Outcome. Open Access Maced J Med Sci. 2019; 7(4): 594-598.

20. Lone FW, Qureshi RN, Emanual F. Maternal anaemia and its impact on perinatal outcome in a tertiary care hospital in Pakistan. Trop Med Int Health 2004;4:486-9.

21. Jones DW, Weiss HA, Changalucha JM, Todd J, Gumodoka B, Bulmer J, et al. Adverse birth outcomes in United Republic of Tanzania-Impact and prevention of maternal risk factors. Bull World Health Organ 2007;85:9-18

22. Shams S. Low birth weight: frequency and association of maternal Factors. Pak Pediatr J. 2012;36(4):192-8.

23. Figueiredo ACMG, Gomes-Filho IS, Silva RB, Pereira PPS, Mata FAFD, Lyrio AO, Souza ES, Cruz SS, Pereira MG. Maternal Anemia and Low Birth Weight: A Systematic Review and Meta-Analysis. Nutrients. 2018;10(5):601. doi: 10.3390/nu10050601. PMID: 29757207; PMCID: PMC5986481. 